\title{
A First Person Perspective on the Congressional Fellowship Experience
}

\author{
Andrew D. Steigerwald
}

"You're a scientist. What kind of bug is this?"

"Ok. Now kill it!"

While this wasn't directed towards me-a colleague in the American Association for the Advancement of Science (AAAS) Congressional Fellowship program related it to me-I find it an apt reflection of how those with scientific backgrounds are viewed in an office filled with nontechnical staff focused on developing policy. Science is viewed as a single, mysterious topic and scientists are viewed as people who know everything about everything, but are too abstracted and oblivious to do anything useful with the knowledge.

I think many on both sides agree that science and technology need to be better integrated into our national policies. Given that technology plays an ever increasing role in our daily lives, one may ask why this hasn't already happened. My suspicion is that the blame lies both with policymakers and the scientific community (and probably in equal amounts). I'll address that later in this article. First, I would like to say a few things about the Congressional Fellowship program in the hope that it will encourage those thinking about applying to take the plunge.

I serve as the 2012-2013 TMS/ MRS Congressional Science and Engineering Fellow in the Office of Senator Sherrod Brown (D-OH). Just to be clear, I don't work for TMS or MRS, or on their behalf. I work for Senator Brown, and I chose his office after a lengthy interview process. AAAS facilitates the overall Science and Technology Policy Fellowship program, and they do an excellent job of helping fellows find an office that is a good fit

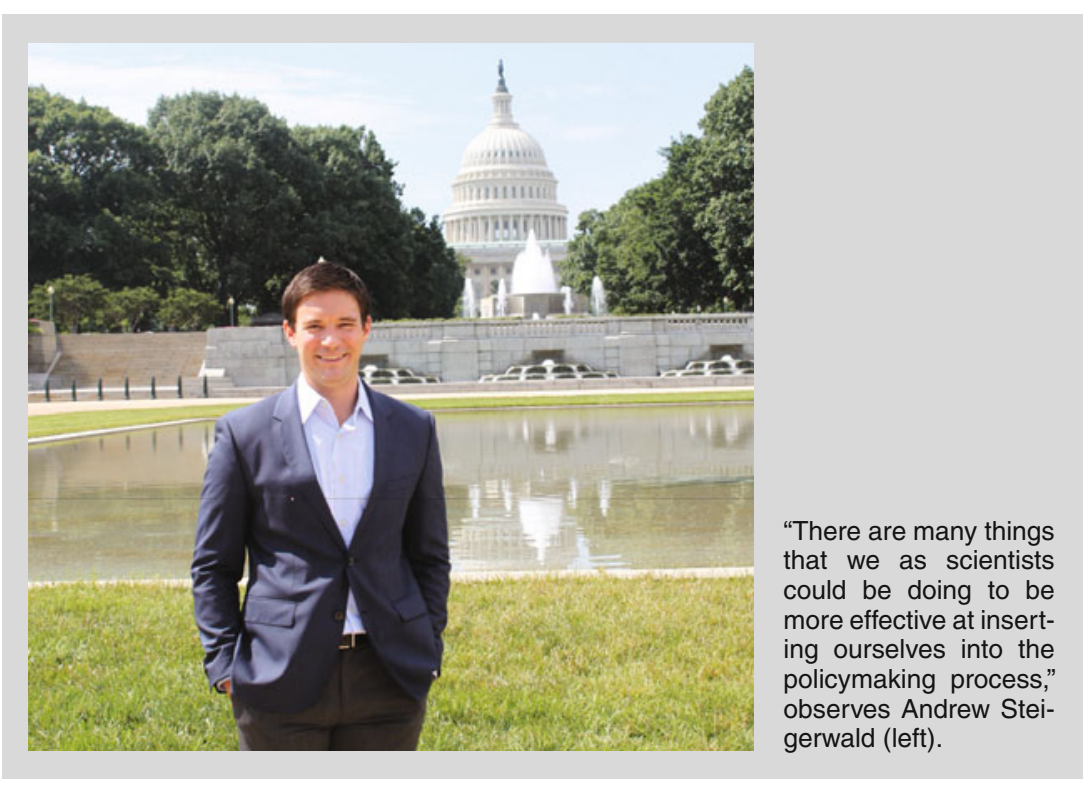

for our career goals and personalities. But to answer a question I get asked a lot, personal politics played a surprisingly minor role in choosing where to do my fellowship.

Throughout the year, I've helped to develop legislation across a (refreshingly) broad range of policy areas, including reforms to the tax code, job creation, clean and renewable energy financing, and advanced manufacturing. I've had the pleasure of serving my fellow Ohioans, whether it's helping small Ohio companies navigate the large federal bureaucracy, talking with individuals about different laws or policies that affect them personally, or helping Ohio universities connect with opportunities at different funding agencies.

As someone who spent six, Gollum-like years in a lab at the end of a hallway with blackout curtains on the windows, the idea that I could meet and work with so many new people every single day is truly amazing. The number of Facebook friends I have has skyrocketed to 160. One hundred and sixty! More seriously, as someone who dealt with unresponsive government and labyrinthine funding processes, helping people interface with their government is one of the most rewarding experiences I've had throughout the fellowship.

Two concerns I often hear from people thinking about pursuing the fellowship are that they feel that they may be wasting the time they invested getting a Ph.D. or they fear they will be behind the curve if they want to return to academic science.

As to the first concern, I use what I learned throughout graduate school and my post-doc many times, in many ways, during an average workday. I don't have many conversations about coherent acoustic phonons in semicon- 
ductors (my thesis topic). However, I have met with a company developing a dual detection ultrasonic-coupled spectrophotometer for the Transportation Security Administration (TSA), a consortia working out manufacturing kinks in a new ultraconductive composite for transmission applications, NASA to discuss its asteroid capture mission, and construction groups interested in novel thin films for building envelope applications. While not my specific areas of expertise, I'm familiar enough with the basic technologies involved that I understand, not only the applications, but why a particular policy may or may not work. Being at this interface between technology, policy, and real-world application is thrilling.

As for the second concern, I feel it's simply not true. Within the AAAS program, I have colleagues who are professors currently on sabbatical, retired professors, medical doctors who will return to practice, people who already have top-tier academic positions lined up, people who want to stay in policy, and people who found that policy wasn't right for them. The fellowship is partly about figuring out what you want to do, and even if you don't stay in policy, you leave with a deep understanding of the government funding process and an extensive network of agency officials and industry contacts. Not many post-docs or young associate professors can boast that.

The fellowship program appealed to me because I wanted to use my background to work on policy that required scientific and technical knowledge to be effective. More importantly, I wanted to be effective at making policy effective. One of the biggest misconceptions - because everyone agrees that we need more technical expertise in policymaking - is that you show up with your technical background and immediately fix the cracks in our national policy like some sort of Ph.D. deus ex machina.

My experience, and possibly the biggest revelation of the fellowship, is that this just isn't true. It's not exactly correct to say that we need more scientific knowledge in the policy process. We need more scientists and engineers and people with technical backgrounds with the right disposition at specific points in the policymaking process. There are many things that we as scientists could be doing to be more effective at inserting ourselves into the policymaking process.

First, a balance needs to be struck between advocating for science and advocating for policies that need more scientific input. While groups often come by to impress the importance of sustained federal investment into all levels of research, rarely does a noninterest group come by to discuss the need for technical input into chemical safety laws, energy tax codes, or infrastructure investment. Groups with technical knowledge do come by to

\section{MEET THE 2013-2014 TMS/MRS CONGRESSIONAL SCIENCE AND ENGINEERING FELLOW}

Megan Brewster will begin making her contributions to the policy making process in

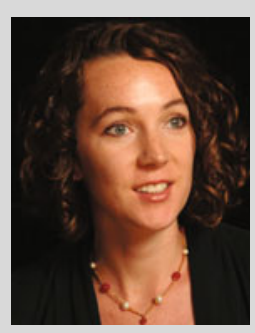

Megan Brewster early September when she starts her one-year term as the 20132014 TMS/MRS Congressional Science and Engineering Fellow.

"The government's ability to unite disparate interests to realize technological innovations has inspired me to pursue a career in federal government," said Brewster, "and the TMS/MRS Congressional Science and Engineering Fellowship offers an exceptional opportunity for me to catapult myself into this nontraditional career path. I look forward to blending my enthusiasm, scientific expertise, and unique world view as a legislative assistant to address the challenges associated with energy, science diplomacy, sustainability, research funding, and shared facilities."

Prior to being named to the fellowship, Brewster was a materials scientist at GE Global Research where she supported the Durathon battery start-up. Her scientific expertise encompassed sodium metal chloride batteries, light-emitting diode/phosphor solid state lighting, and CdZnTe radiation detectors. She also led the GE Global Research myConnections initiative for the GE Women's Network Schenectady Hub.

Brewster received her Ph.D. in material science and engineering from the Massachusetts Institute of Technology (MIT). Her doctoral work, funded by National Science Foundation and the Department of Defense fellowships, led to a deeper understanding of fundamental energy carriers in individual semiconductor nanostructures. She also minored in technology and policy and served as co-president of the Science Policy Initiative (SPI) student group.

"My interest in science policy began during my doctoral studies at MIT, through the Science Policy Initiative (SPI)," said Brewster. "SPI is a student group that seeks to introduce young scientists and engineers to science policy, and I enthusiastically participated in all of their programming - first a science policy 'boot camp' short course, followed by visits with staffers during Congressional Visits Day (CVD). During boot camp, I was particularly inspired by the proven ability of the federal government to play a unique role in the global scientific enterprise by pairing scientific ingenuity with market urgency through policies and programs to form powerhouse teams capable of realizing transformative technologies. The CVD experience helped me realize how critical the scientist's voice is to the legislative process, both in addressing specific science policy issues, as well as to share the process by which scientific knowledge is built with policy makers."

Brewster has also gained laboratory experience with ceramics, optical fibers, phosphors, biomaterials, neurobiology, and graphene. She earned her B.S. in materials science and engineering from the University of Washington.

As noted in Andrew Steigerwald's accompanying article, Brewster's first few weeks of her fellowship will be comprised of an intensive science policy orientation facilitated by the AAAS. Following orientation, she will go through an interview and selection process with offices of senators, representatives or committees on Capitol Hill. Offices will then extend offers, and she will choose where she will spend her fellowship year.

In commenting on Brewster's selection, Ed Herderick, Chair, TMS Public \& Governmental Affairs Committee, member of the Congressional Fellowship Selection Committee, and a former Congressional Fellow himself, said, "The Congressional Fellowship program is an important avenue for the materials community to support informed policy making. Policy issues are becoming ever more complex technologically, and Megan is well poised to make a strong contribution applying both her materials expertise and excellent communication skills." 


\section{ARE YOU THE NEXT CONGRESSIONAL SCIENCE AND ENGINEERING FELLOW?}

Starting in September, TMS and the Materials Research Society (MRS) will accept applications for the 2014-2015 TMS/MRS Congressional Science and Engineering Fellowship.

To be considered for the fellowship, applicants must have a record of success in research or scholarship in a field relevant to materials science, while also demonstrating a strong interest in applying scientific and technical knowledge to U.S. public policy issues. Additional critical qualities include the ability to work quickly and communicate effectively to both scientific and non-scientific audiences on a wide variety of topics, as well as being able to work cooperatively with individuals having diverse viewpoints. An applicant is expected to be a member or an applicant for membership of TMS or MRS, and must have a Ph.D. by September 1, 2014. U.S. citizenship is not required, but applicants must be authorized to work in the United States.

The American Association for the Advancement of Science Congressional Science and Engineering Fellows Program is operated as a cooperative effort of approximately 30 national scientific and engineering societies that provide an opportunity for accomplished scientists and engineers with public policy interests to learn about and contribute to the policy-making processes in Congress.

For additional information on the 2014-2015 TMS/MRS Congressional Science and Engineering Fellowship, contact Mary Samsa, TMS Foundation and Public Affairs Manager, atmsamsa@tms.org.

\section{TMS MGI EXECUTIVE BRANCH FELLOWSHIP EXTENDED}

A prestigious fellowship with placement in the White House Office of Science and Technology Policy (OSTP) and focusing on the policy development process related to the

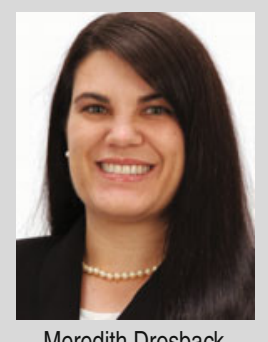

Meredith Drosback Materials Genome Initiative (MGI) has been extended from one year to 18 months. The original fellowship and its extension are sponsored by TMS as part of its ongoing commitment to foster a new era of materials innovation, as embodied by the MGI. The incumbent TMS MGI Fellow, Meredith Drosback, who started her appointment on September 1, 2012, will continue to work with senior OSTP and Administration officials to synthesize materials science and engineering information pertinent to policy issues, present analysis to senior policy makers, and recommend data collection needs and requirements.

discuss these topics-They are the groups sent in by a chemical company, or an oil producer, or an environmental group.

The result is twofold. First, science tends to become reduced to another voice out of hundreds asking for more money. That devalues how people view science and scientists as a resource. Second, the technical input entering the policy process becomes inherently biased. It's impossible for an average staff member to determine the best course when being hammered with a technical hailstorm coming from both extremes. I firmly believe that if the scientific community doesn't fill this "neutral input" role, no one will.

Second, universities - especially those that view themselves as research institutions - need to integrate policy studies into technical curriculum. Personally, I would make some form of policy coursework a requirement for every science and engineering student, both at the undergraduate and graduate level. What is more useful to a budding scientist-learning how to determine the potential between two concentric spheres divided into hemispheres by a horizontal plane or learning how to navigate the federal funding process and understanding the funding cycle? (Not to pick on graduate electromagnetics, but that was never terribly useful in writing a grant.)

Further, universities should fund 12-24 week placements for science and engineering students in congressional offices. This would create a generation of scientists and engineers with hands-on knowledge of the nuances of public policy, connections within the funding process, and experience in effectively advocating on issues.

Third, following the previous sug- gestion, congressional offices should have at least one full-time member on staff with an advanced technical background. We can't force offices to change their hiring practices, but here's the rub: To be considered for a position on Capitol Hill, you almost always need previous Hill experience (a sort of Catch-22 that is emblematic of how things work). A broad universitydriven internship program will provide offices with a pool of talented scientists and engineers who also have Hill experience.

There are many more things we as a scientific community could do to facilitate technically sound policy, but these would be a good start. It goes without saying that technology will increasingly permeate society. However, there is no reason to believe that our technical policy will be able to keep pace. In other words, if you think it's bad in 2013, imagine 2033.

As I was writing this article, the $\mathrm{Su}-$ preme Court handed down a decision on gene patenting. While the decision seems somewhat sound, Justice Antonin Scalia wrote in a dissenting opinion that "I am unable to affirm those details on my own knowledge or even my own belief." Issues like this will become ever more common, and there is no clean, single-shot solution. It is incumbent upon us as scientists to be more active in the policymaking process.

As for myself, I want to work not only on science and technology policy, but to also use my science and technology background to better facilitate effective energy, environment, and infrastructure polices that benefit the middle class and spur economic growth. I plan to continue in policy, and hope that more and more scientists and engineers look at policy as something complementary to their scientific background, and get involved either through the fellowship program or any other-and hopefully increasingly available - channels.

Prior to his appointment as the 2012-2013 TMS/ MRS Congressional Science and Engineering Fellow, Andrew D. (Drew) Steigerwald was a postdoctoral research associate at Vanderbilt University and consulted with Femtometrix, Inc. He earned his doctorate in interdisciplinary materials science from Vanderbilt University. 